\title{
Transmission Electron Microscopy Characterization of IONPs Modified with Polyethylene Glycol Derivatives
}

\author{
A. Lagar-Sosa ${ }^{1}$, M. Muñoz-Arias ${ }^{1,2}$, A. Lugo-Calas ${ }^{2}$, M. P. Hernández ${ }^{3}$, A. M. Díaz-García ${ }^{1 *}$ and C. \\ Lariot $^{3}$
}

1. Faculty of Chemistry, University of Havana, Havana, Cuba

2. Finlay Vaccines Institute, Havana, Cuba

3. IMRE, Havana University, Havana, Cuba

*Corresponding author: adg1959@gmail.com

Iron oxide nanoparticles (IONPs) received great attention due to its potential use as platform for medical and pharmaceutical applications.[1,2] A protective layer on the IONPs surface is necessary for avoid the aggregation and, then, stabilize the dispersion. In some cases, this modification permits the interaction with others molecules or biomolecules. Wide coatings agents were used, some of them are polyethylene glycol derivatives. Polyethylene glycol (PEG) ensures the biocompatibility of these nanoparticles.[3]

The main goal of this work is to compare the size of IONPs covered with two different PEG derivatives: $\quad$ PEG-1kDa- $\left(\mathrm{COCH}_{2} \mathrm{CH}_{2} \mathrm{COOH}\right)_{2}$ and PEG-3kDa-(CONHNH$\left.)_{2}\right)$. IONPs were synthetized by coprecipitation method. IONPs@PEG-1kDa- $\left(\mathrm{COCH}_{2} \mathrm{CH}_{2} \mathrm{COOH}\right)_{2}$ and IONPs@PEG$\left.3 \mathrm{kDa}-\left(\mathrm{CONHNH}_{2}\right)_{2}\right)$ were obtained by in situ and post-synthesis methodologies, respectively. IONPs were characterized by attenuated total reflectance (ATR). In both cases, the vibration band of C-O-C around $1100 \mathrm{~cm}^{-1}$ was observed. This fact suggests the presence of PEG chains on the surface of nanoparticles in comparison with uncoated IONPs.

A quasi-spherical morphology was detected through transmission electron microscopy (TEM). A better control of the size and shape results when the IONPs were obtained by in situ methodology. IONPs@PEG-1kDa- $\left(\mathrm{COCH}_{2} \mathrm{CH}_{2} \mathrm{COOH}\right)_{2}$ has a core diameter of $6,7 \pm 0,9 \mathrm{~nm}$ and 13,7 $\pm 1,3 \mathrm{~nm}$ for IONPs@PEG-3kDa-(CONHNH$\left.)_{2}\right)_{2}$. This study supports the influence of ligands addition during the process of nanoparticles formation.

Diffractograms permits to assign the different families of planes corresponding to spinel structure of iron oxides (magnetite, $\mathrm{Fe}_{3} \mathrm{O}_{4}$ and maghemite, $\gamma-\mathrm{Fe}_{2} \mathrm{O}_{3}$ ) comparing with IONPs with no organic layer obtained also by coprecipitation method. Families of planes (220) were observed in IONP@PEG$1 \mathrm{kDa}-\left(\mathrm{COCH}_{2} \mathrm{CH}_{2} \mathrm{COOH}\right)_{2}$ and planes (111) and (311) of the IONP@PEG-3kDa- $\left(\mathrm{CONHNH}_{2}\right)_{2}$, by amplification of TEM images.

Conclusions

Synthesis of IONPs@PEG-1kDa- $\left(\mathrm{COCH}_{2} \mathrm{CH}_{2} \mathrm{COOH}\right)_{2}$ obtained by in situ addition and IONPs@PEG-3kDa-(CONHNH$\left.)_{2}\right)_{2}$ ) by post-synthesis methodologies shows that the presence of polymeric ligand during the nanoparticles formation contributes significantly to produce smaller IONPs. 
References:

[1] C. Felton, A. Karmakar, Y. Gartia, P. Ramidi, A. S. Biris, A. Ghosh, Drug. Metab. Rev., 46(2) (2014) p. 142-154.

[2] D. Lombardo, M. A. Kiselev, M. T. Caccamo, Journal of Nanomaterials, (2019) Article ID 3702518, 26 pages.

[3] B. Pelaz, P. del Pino, P. Maffre, R. Hartmann, M. Gallego, S. Rivera-Fernández, J. M. de la Fuente, G. Ulrich Nienhaus, W. J. Parak, ACS Nano 9(7) (2015), p. 6996-7008.
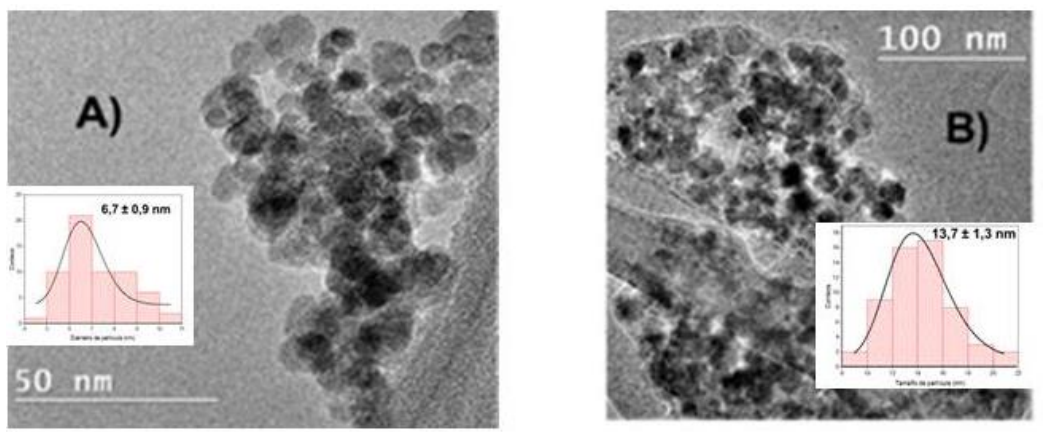

Figure 1. Transmission electron microscopy images and histograms of the IONP@PEG-1kDa$\left(\mathrm{COCH}_{2} \mathrm{CH}_{2} \mathrm{COOH}\right)_{2}$ obtained by in situ addition (A) and the IONP@PEG-3kDa- $(\mathrm{CONHNH})_{2}$ synthesized with post-synthesis addition (B).
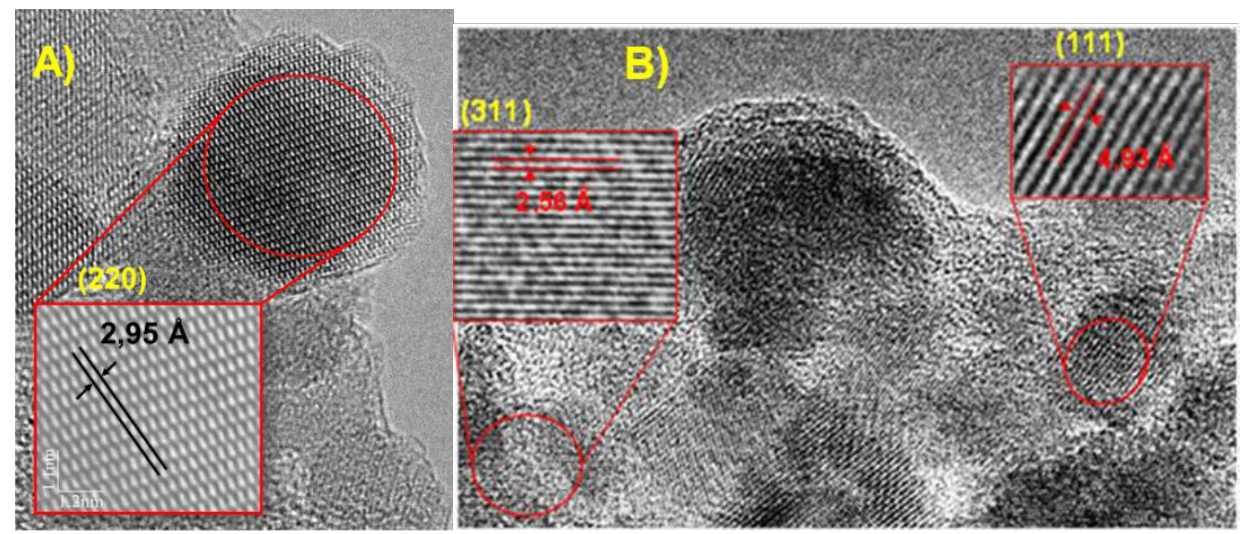

Figure 2. Approach of the TEM images, showing planes (220) in the IONP@PEG-1kDa$\left(\mathrm{COCH}_{2} \mathrm{CH}_{2} \mathrm{COOH}\right)_{2}(\mathbf{A})$ and planes (111) and (311) of the IONP@PEG-3kDa- $\left(\mathrm{CONHNH}_{2}\right)_{2}(\mathbf{B})$.

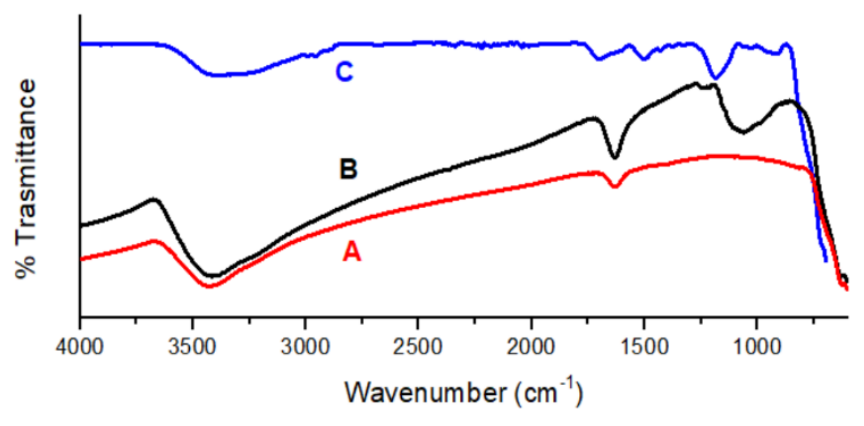

Figure 3. Attenuated Total Reflectance spectra of uncoated IONPs (A), IONP@PEG-3kDa$\left(\mathrm{CONHNH}_{2}\right)_{2}$ (B) and IONP@PEG-1kDa$\left(\mathrm{COCH}_{2} \mathrm{CH}_{2} \mathrm{COOH}\right)_{2}(\mathbf{C})$.

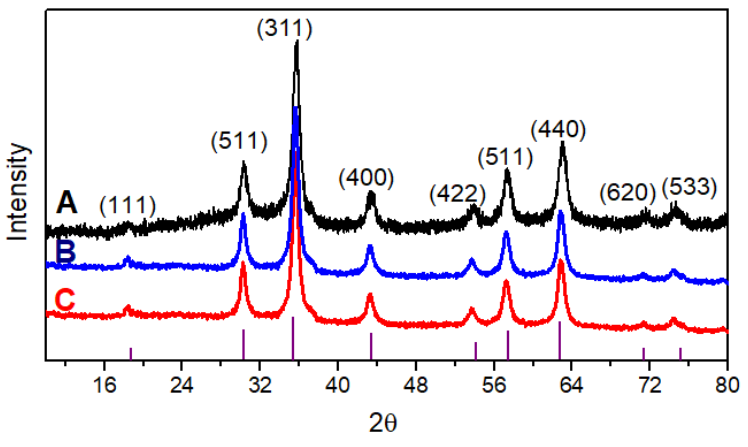

Figure 4. Diffractograms of the IONP@PEG$1 \mathrm{kDa}-\left(\mathrm{COCH}_{2} \mathrm{CH}_{2} \mathrm{COOH}\right)_{2}(\mathbf{A})$, the uncoated IONP (B) and the IONP@PEG-3kDa$\left(\mathrm{CONHNH}_{2}\right)_{2}(\mathbf{C})$. 